\title{
Los operadores de comercio exterior: la nueva propuesta de la Ley General de Aduanas
}

Javier Alonso Caballero Caballero

Abogado por la Universidad San Martín de Porres. Maestría en Derecho con mención en Derecho Internacional Económico por la Pontificia Universidad Católica del Perú. Profesor de la Escuela de Comercio Exterior de la Asociación de Exportadores.

SUMARI0:

I. Introducción.

II. El operador de comercio exterior.

III. El papel de la Administración Aduanera.

IV. A manera de conclusión. 


\title{
RESUMEN:
}

El nuevo decenio ofrece grandes posibilidades de éxito para las empresas vinculadas al comercio exterior cuya calidad y eficiencia las diferencie en el mercado. El comercio exterior requiere reducir tiempos y costos, dentro de un comercio ágil, lícito y seguro. Es importante conocer los mecanismos que ofrecen ventajas competitivas para ello.

Palabras clave: comercio exterior, operador, Ley General de Aduanas, operador económico autorizado, Tiempo Total de Liberación de Mercancías

\begin{abstract}
:
The new decade offers great possibilities of success for international commerce-related companies, whose quality and efficiency sets them apart from the competition. International commerce requires reducing timeframes and costs, all of this within an agile, legal and safe commerce. It is important to know the mechanisms that offer competitive advantages to this end.

Keywords: international commerce, operator, General Law of Customs, authorized economic operator, total time of merchandise release
\end{abstract}

\section{INTRODUCCIÓN}

La dinámica del comercio internacional es un aspecto fundamental a considerar en la buena marcha de la economía de un país. El Perú no es ajeno a esta regla de comercio, más aún desde la liberalización de su economía en la década de los noventa y la gran importancia que tiene el comercio exterior en el crecimiento de su economía.

Es así como la participación adecuada de las partes intervinientes en el proceso de ingreso de las mercancías al país generará un esquema de "ganar - ganar" en beneficio de todos, a través de la intervención eficiente de cada parte y la creación de una sinergia entre todos, destinada a reducir los tiempos y costos del comercio.

Ello constituye una necesidad para el país que se manifiesta a través de la mejora de los tiempos de atención de dicho proceso que, a su vez, contribuye a potenciar la competitividad del comercio exterior peruano, reducir tiempos y costos y a mejorar la seguridad de la cadena logística.

Como es sabido, los tiempos en el comercio exterior tienen relación directa con los costos. Es por ello que la reducción de tiempos de la cadena logística de ingreso de las mercancías implicará la reducción de costos del comercio y a su vez, el aumento de la competitividad del mismo.

\section{EL OPERADOR DE COMERCIO EXTERIOR}

Es en este escenario que el sector privado tiene una intervención relevante, en su calidad de operador de comercio exterior en la cadena logística de ingreso de las mercancías al país.

En efecto, las personas naturales y jurídicas que participan activamente en la referida cadena logística con su intervención específica en cada una de las etapas del ingreso de las mercancías, necesaria e impostergablemente, deberán desarrollar su accionar de manera eficiente como mejor garantía del éxito del negocio de su cliente, con la reducción de tiempos y costos para éste.

En nuestro país, la Ley General de Aduanas vigente, aprobada por Decreto Legislativo 1053', establece taxativamente las obligaciones a las que se encuentra sujeto cada operador de co-

1. La vigente Ley General de Aduanas fue aprobada por Decreto Legislativo 1053 y fue publicada en el Diario Oficial El Peruano el 27 de junio del 2018. 
mercio exterior en función a su participación en la cadena logística; considerando que, en caso de incumplimiento, éste incurre en infracción tipificada en la misma ley sujeta a sanción de multa, suspensión, cancelación, inhabilitación o comiso de las mercancías, según sea el caso del supuesto de la infracción.

Es importante resaltar que con la expedición del Decreto Legislativo $1433^{2}$ se modificó diversos artículos de la citada Ley General de Aduanas, entre ellos, los referidos a los operadores de comercio exterior, produciéndose una distinción relevante en el concepto de "operador de comercio exterior", término general empleado a lo largo de la legislación aduanera nacional para comprender a cualquier persona natural o jurídica interviniente o beneficiaria, por sí o por otro, en los regímenes aduaneros previstos en la Ley General de Aduanas, sin excepción alguna.

Además, dicha modificación legislativa establece determinados lineamientos para la autorización de los operadores de comercio exterior por parte de la Administración Aduanera e inclusive éstos son categorizados a fin de otorgarles tratamientos diferenciados en base a un ranking soportado en su performance en el quehacer aduanero, aspecto novedoso en nuestra legislación aduanera.

En efecto, el nuevo marco normativo nacional divide el término de "operador de comercio exterior" distinguiendo al "operador de comercio exterior" - propiamente dicho-y considerándolo como aquella persona natural o jurídica que es autorizada por la Administración Aduanera para operar como tal en el quehacer aduanero, refiriéndose en específico al despachador de aduana, transportista o su representante en el país, operador de transporte multimodal internacional ${ }^{3}$, agente de carga internacional, almacén aduanero, empresa de servicio postal, empresa de servicio de entrega rápida, almacén libre - duty free-, beneficiario de material para uso aeronáutico, asociación garantizadora ${ }^{4}$ y a la asociación expedidora. ${ }^{5}$

Asimismo, comprende al "operador interviniente", considerando dentro del él al importador, exportador, beneficiario de los regímenes aduaneros, pasajero ${ }^{6}$, administrador o concesionario de las instalaciones portuarias, aeroportuarias o terminales terrestres internacionales, opera-

2. El Decreto Legislativo 1433 fue emitido en el marco de las facultades delegadas al Poder Ejecutivo para legislar en materia de gestión económica y competitividad, entre otros, mediante la Ley 30823. Dicho Decreto Legislativo fue publicado en el Diario Oficial El Peruano el 16 de setiembre del 2018.

3. De acuerdo al artículo 19 de la Ley General de Aduanas, modificada por el Decreto Legislativo 1433, el operador de transporte multimodal internacional es el que por sí o por medio de otro que actúe en su nombre, celebra un contrato de transporte multimodal en virtud del cual expide un único documento de transporte multimodal, asumiendo la responsabilidad de su cumplimiento. El operador de transporte multimodal actúa como principal, no como agente o por cuenta del expedidor o de los porteadores que participan en las operaciones de transporte multimodal y cuenta con la autorización de la entidad pública correspondiente.

4. Conforme a la norma antes anotada, la asociación garantizadora es aquella que, en el marco del Convenio Relativo a la Importación Temporal, garantiza las obligaciones del régimen de admisión temporal para reexportación en el mismo estado y está afiliada a una cadena de garantía.

5. Según la misma norma anterior, la asociación expedidora es aquella que, en el marco del Convenio Relativo a la Importación Temporal, expide los títulos de importación temporal para el régimen de admisión temporal para reexportación en el mismo estado y está afiliada directa o indirectamente a una cadena de garantía.

6. La Cuarta Disposición Complementaria Final del Reglamento de la Ley General de Aduanas, aprobado por Decreto Supremo N³67-2019-EF, sustituye el término "viajero" por "pasajero" en el Reglamento del Régimen Aduanero Especial de Equipaje y Menaje de Casa, aprobado por el Decreto Supremo N ${ }^{\circ} 182-2013-E F$. Se estima que esta distinción busca otorgar precisión al término de este operador interviniente. 
dor de base fija ${ }^{7}$, al laboratorio ${ }^{8}$, al proveedor de precinto ${ }^{9}$ y en general, a cualquier persona natural o jurídica interviniente en un régimen o trámite aduanero o en una operación relacionada a aquellos, pero que no sea considerado un operador de comercio exterior, empleando un criterio de exclusión.

Finalmente, distingue al "tercero", aplicando un criterio de exclusión adicional, en la medida que lo considera como aquél vinculado a la operatividad aduanera o a otra operación relacionada a ésta, que no califique como operador de comercio exterior u operador interviniente.

Además de esta nueva clasificación, el nuevo marco normativo establece determinados lineamientos para que la Administración Aduanera pueda otorgar al operador de comercio exterior la autorización respectiva para que pueda desempeñarse como tal y con ello, poder participar en el flujo del comercio internacional de las mercancías.

Estos lineamientos implican acreditar contar con la autorización, el certificado, el registro, la licencia o el nombramiento otorgado por entidad pública competente, expedidos de manera previa al operador, la trayectoria satisfactoria de cumplimiento - en el ámbito tributario y aduanero-, la trazabilidad de sus operaciones, la solvencia financiera, la continuidad del servicio entendida como la cantidad o volumen de servicios $\mathrm{u}$ operaciones aduaneras mínimas en un periodo determinado, el sistema de seguridad y el sistema de gestión de la calidad.

Dichos lineamientos han sido establecidos a fin de que la Administración Aduanera pueda otorgar esta condición de operador de comercio exterior para la intervención en la cadena logística del comercio exterior a las personas naturales o jurídicas que sean plenamente identificables, potencialmente confiables y seguras como mecanismo para garantizar un flujo de comercio ágil y seguro de la cadena logística.

Adicionalmente, en el caso de los operadores de comercio exterior, es decir, de aquellas personas que requieren autorización de la Administración Aduanera para intervenir en el quehacer aduanero y como resultaba necesario para estimular la eficiencia en el desempeño, se ha establecido determinadas categorías en función a su nivel de cumplimiento y la calidad del servicio que prestan.

Dichas categorías son tomadas en cuenta por la Administración Aduanera para la renovación de la autorización del operador, el determinar la modalidad y el monto de la garantía a otorgar, el no sancionar los supuestos de infracción leve y la aplicación de la gradualidad en materia aduanera.

Las categorías de operador de comercio exterior y sus rangos de calificación son:

7. El operador de base fija es un operador interviniente que es el principal proveedor de servicios de apoyo a la aviación en general a los operadores en un aeropuerto determinado, por ejemplo, el abastecimiento de combustible, el mantenimiento de aeronaves u otros servicios similares.

8. El laboratorio ha sido incorporado como operador interviniente en la medida de su importancia cada vez más creciente en la determinación de las características merceológicas de las diversas mercancías objeto del comercio internacional a fin de que, en base a ellas, se pueda establecer su correcta clasificación arancelaria, conforme al Arancel de Aduanas.

9. El proveedor de precinto ha sido incorporado como un operador interviniente en función a la importancia que tiene el precinto aduanero en la seguridad de la cadena logística. El Procedimiento Aduanero CONTROL —PE.00.08— Uso y control de precintos aduaneros y otras medidas de seguridad —versión No. 2-, aprobado por Resolución de Intendencia Nacional N²5-2018/SUNAT/310000 del 17 de julio del 2018, establece las pautas para el registro, control, uso y verificación de los precintos aduaneros destinados a la custodia y protección de la carga transportada en contenedores cerrados, y vehículos tipo furgón o cisternas cuando su estructura y acondicionamiento permita su precintado, así como otras medidas de seguridad. 
a) Categoría $\mathrm{A}$-nivel de cumplimiento mayor o igual al $90 \%$ -

b) Categoría B —nivel de cumplimiento mayor o igual a $60 \%$ y menor a $90 \%$ -

c) Categoría C - nivel de cumplimiento menor al $60 \%$ -

El nivel de cumplimiento es medido por la propia Administración Aduanera y se califica en función a las infracciones determinadas a cada operador de comercio exterior, de acuerdo a lo establecido en la Tabla de Sanciones, en la que se clasifica la gravedad de la sanción - como leve, grave o muy grave-, individualiza al infractor, especifica los supuestos de infracción —vinculadas a las autorizaciones, al manifiesto y actos relacionados, a la declaración, a otra información, al control aduanero y a la seguridad-, fija la cuantía de las sanciones y se desarrolla las particularidades para su aplicación.

En suma, nuestro marco normativo actual, con el establecimiento de las referidas categorías en el caso de los operadores de comercio exterior, privilegia la eficiencia en su desempeño, elemento clave para el impulso de la competitividad del comercio exterior y el establecimiento y mejora de las sinergias con la Administración Aduanera; los otros operadores de comercio exterior, operadores intervinientes y terceros para la reducción de tiempos y costos y la mejora de la seguridad de la cadena logística.

Nuestro país necesita de un comercio ágil, legítimo y seguro. Es una tarea de todos los involucrados en este proceso por lo que la selección de los mejores operadores de comercio exterior será clave para ello.

Sin duda, la creación y difusión de la figura del Operador Económico Autorizado - OEA en el Perú ha sido muy importante en la orientación de la novísima regulación de los demás operadores de comercio exterior.

En cuanto al Operador Económico Autorizado, cabe recordar que la Organización Mundial de Aduanas - OMA en el año 2015 aprobó el MARCO SAFE de Estándares - WCO SAFE Framework of Standards - con el objetivo de garantizar la facilitación y la seguridad del comercio internacional a través de la circulación fluida de las mercancías mediante cadenas logísticas internacionales seguras. Este marco normativo se respalda en tres pilares fundamentales de colaboración: Aduanas-Aduanas, Aduanas-Empresas y Aduanas-Otros Gobiernos y Agencias Gubernamentales.

El Operador Económico Autorizado nace dentro del pilar Aduanas-Empresas y busca establecer una relación de confianza mutua entre ambas y además se orienta a crear el marco apropiado para que las empresas participen de manera activa en la seguridad de la cadena logística de las mercancías materia de comercio exterior.

En el Perú, el Operador Económico Autorizado se implementó con la dación de la vigente Ley General de Aduanas, siendo la Administración Aduanera la encargada de otorgar la certificación a importadores, exportadores, agentes de aduana, almacenes autorizados y empresas de servicios de entrega rápida ESER, que son los operadores de comercio comprendidos en dicho programa.

El Operador Económico Autorizado es aquel operador de comercio exterior u operador interviniente, certificado por la Administración Aduanera, al haber cumplido con las condiciones y requisitos establecidos en la referida Ley y sus normas reglamentarias, conforme lo define el artículo 25 del Decreto Legislativo 1433.

En cuanto a las condiciones, ellas son similares a las requeridas a los operadores de comercio exterior para que la Administración Aduanera los pueda autorizar a operar, en cuanto a trayectoria satisfactoria de cumplimiento de la normativa vigente — tributaria y aduanera-, sistema de registro que permita la trazabilidad de sus operaciones, solvencia financiera y nivel de seguridad adecuado.

Es un operador de confianza para la Administración Aduanera, de bajo riesgo para ella y en base a ello, ésta le permite acogerse a facilidades en el control y la simplificación aduanera aplicables sólo a ellos, como por ejemplo pre-

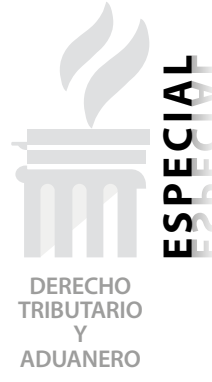

(n)


sentar una sola declaración aduanera de mercancías que ampare los despachos que realice en un plazo determinado, presentar una declaración inicial con información mínima para el levante de las mercancías, presentar garantías reducidas o estar exento de su presentación, efectuar directamente sus despachos sin necesidad de contar con el servicio de un despachador de aduana y obtener otras facilidades que la Administración Aduanera establezca.

El OEA constituye un objetivo estratégico para la Administración Aduanera, así como un objetivo-país de la Agenda de Competitividad Nacional con miras al ingreso del Perú a la Organización para la Cooperación y el Desarrollo Económicos - OCDE, por su impacto directo en la reducción de tiempos y costos en el comercio exterior peruano.

En suma, el OEA constituye un operador de comercio exterior $u$ operador interviniente confiable para la Administración Aduanera cuyo número de empresas certificadas se ha venido incrementando a lo largo de los años y que fortalece el pilar Aduanas-Empresas del Marco SAFE de la OMA.

Ello permite que la Administración Aduanera pueda abocar sus acciones de control aduanero hacia las operaciones de mayor riesgo, racionalizando el empleo de sus recursos y facilitando el comercio exterior legítimo y seguro; y para los operadores de comercio exterior y operadores intervinientes constituye una oportunidad para obtener facilidades en el control y simplificación aduaneros que redundarán en la reducción de tiempos y costos de las operaciones a su cargo.

\section{EL PAPEL DE LA ADMINISTRACIÓN ADUANERA}

En este escenario, la Administración Aduanera no puede permanecer ajena y pasiva al esfuerzo de mejora continua exigida a los operadores de comercio exterior, acorde a lo señalado en los párrafos anteriores; por el contrario, debe continuar su mejora con la virtualización, simplificación y racionalización de sus procedimientos operativos y trámites aduaneros como garantía de facilitar cada vez más el comercio exterior legítimo y seguro.

Ella cumple un rol importante mediante el empleo racional de su prerrogativa legal de control aduanero sobre las mercancías, personas y medios de transporte en el comercio internacional, orientando sus acciones de control hacia las operaciones de mayor riesgo y flexibilizándolas respecto a las de menor riesgo, como garantía de un adecuado flujo en nuestro comercio internacional y de facilitación del comercio exterior legítimo.

Cabe recordar que la Administración Aduanera es el órgano de la Superintendencia Nacional de Aduanas y de Administración Tributaria SUNAT competente para aplicar la legislación aduanera, recaudar los derechos arancelarios y demás tributos aplicables a la importación para el consumo, aplicar otras leyes y reglamentos relativos a los regímenes aduaneros y ejercer la Potestad Aduanera. ${ }^{10}$

En tal sentido, la Administración Aduanera ha venido liderando en estos últimos años un esfuerzo conjunto con los operadores del comercio exterior a fin de reducir sustancialmente los tiempos del despacho aduanero de las mercancías. Ello a través de la implementación y seguimiento constante del indicador denominado "Tiempo Total de Liberación de Mercancías" - TTLM, que es un indicador estratégico de la institución que mide el tiempo de demora una carga desde la llegada del medio de transporte que la trae al país hasta que es despachada y obtenido su levante, momento

10. El artículo 164 de la Ley General de Aduanas define a la Potestad Aduanera como el conjunto de facultades y atribuciones que tiene la Administración Aduanera para controlar el ingreso, permanencia, traslado y salida de personas, mercancías y medios de transporte, dentro del territorio aduanero, así como para aplicar y hacer cumplir las disposiciones legales y reglamentarias que regulan el ordenamiento jurídico aduanero. 
en el cual el dueño o consignatario puede disponer libremente de su mercancía.

La medición de este tiempo, en el caso del despacho diferido ${ }^{11}$, comprende cinco fases claramente diferenciadas, que van desde la llegada del medio de transporte hasta el término de la descarga -Fase 1-; desde el término de la descarga hasta el ingreso de la mercancía al almacén aduanero -Fase 2-; desde el ingreso de la mercancía al almacén aduanero hasta la numeración de la declaración aduanera de mercancías -Fase 3-; desde la numeración de la declaración aduanera de mercancías hasta el pago de los tributos de importación -Fase 4-; y por último, desde el pago de los tributos de importación hasta el otorgamiento del levante -Fase 5-.

Este indicador estratégico busca medir el tiempo total de despacho en el régimen aduanero de importación para el consumo a fin de otorgar transparencia a la información del proceso a lo largo de sus cinco fases, así como fomentar el incremento de la eficiencia en los intervinientes en el proceso e impulsar la competitividad del comercio exterior con la reducción de tiempos y costos, en realidad se trata de un esfuerzo de crear sinergia en general entre todos los intervinientes en el proceso, incluida por cierto la propia Administración Aduanera.

EI TTLM constituye un gran esfuerzo que va mucho más allá del campo de acción directa de la Administración Aduanera que se vería reflejada sólo en la Fase 4 del proceso, ya que incluye labores directas de los operadores del comercio exterior en las demás fases del proceso, como son los transportistas o sus representantes, almacenes aduaneros, despachadores de aduanas, importadores y otros vinculados, tiempos que se encuentran debidamente registrados en el TTLM y cuya información es de acceso al público a través del portal web de la SUNAT.
En efecto, ello se explica por cuanto la medición que se realiza en el TTLM comprende desde la llegada del medio de transporte hasta el levante de las mercancías en las principales Intendencias de Aduana del Perú, a fin de impulsar la reducción de tiempos continua, a nivel nacional, en toda la cadena logística de la importación de mercancías.

Este nuevo reto implicará necesariamente un gran esfuerzo coordinado de la Administración Aduanera con los operadores del comercio exterior en el proceso de ingreso de la carga a nuestro país, articulando esfuerzos a fin de potenciar las sinergias que se han venido construyendo en estos últimos años con el mismo objetivo, enmarcado en los alcances del Acuerdo de Facilitación de Comercio de la Organización Mundial de Aduanas - OMA del que nuestro país forma parte. La reducción de tiempos y costos del comercio exterior es clave para potenciar su competitividad.

Finalmente, un nuevo reto a asumir a futuro debería ser que esta medición no se limite sólo al flujo de ingreso de las mercancías para el régimen de importación al consumo sino que se amplíe a los demás regímenes aduaneros de ingreso que requieran una disposición de la mercancía de manera ágil por el interesado e inclusive a los regímenes de salida, particularmente en el régimen de exportación definitiva en el que potenciar la competitividad e clave para el país, sin que ello implique descuidar el control aduanero y la necesaria prevención y combate al fraude aduanero.

\section{A MANERA DE CONCLUSIÓN}

En suma, nos encontramos ante un nuevo escenario de regulación de los operadores de comercio exterior que ofrece grandes posibilidades de éxito a aquéllos que se distingan de los demás por su desempeño eficiente,

11. El despacho diferido es una de las modalidades del despacho aduanero que se presenta cuando se numera la declaración aduanera de mercancías - DAM después de la llegada del medio de transporte, a diferencia de la modalidad de despacho anticipado, cuya declaración se numera antes de la llegada del medio de transporte. 
acorde a los nuevos estándares que fijan la Ley General de Aduanas, su Reglamento y los Procedimientos Aduaneros vinculados y, por qué no decirlo, a través del registro de la información en el TTLM respecto a los tiempos de su participación en la cadena logística de ingreso de las mercancías de comercio exterior a nuestro país.

La eficiencia será la condición clave para la selección del operador por parte de los interesados, los cuales podrán contar con información pública oficial respecto a su performance reflejada en la categoría asignada, los tiempos de demora en las operaciones a su cargo que el TTLM provea. De esta forma se constituirá la mejor elección de operadores, debidamente preparados a afrontar grandes retos.

Todo ello, sumado a la participación necesariamente eficiente de la Administración Aduanera en el proceso, con la virtualización y simplificación de los procedimientos aduaneros y el enfoque racional de sus acciones de control, así como en la asignación objetiva de las categorías a cada operador de comercio exterior en base a su real desempeño en el quehacer aduanero, privilegiando la calidad y excelencia, permitirá sostenidamente aumentar la competitividad del país, con la reducción de tiempos y costos del comercio y mejorar la seguridad de la cadena logística. 